\title{
Voltage Stability Assessment of the Polish Power Transmission System
}

\author{
Robert Lis \\ Faculty of Electrical Engineering, Wroclaw University of Science and Technology, Poland, \\ Robert. Lis@pwr.edu.pl
}

\begin{abstract}
PSE S.A. is the sole Transmission System Operator in Poland and, as such, responsible for the provision of reactive power resources for maintaining the voltage within predefined limits. This paper describes the problems associated with the investigation of voltage stability of transmission power grid. Voltage problems are the result of heavy loading of transmission lines and transformers. Voltage instability has been responsible for voltage damage in some parts of Polish Power Transmission System (PPTS) on 26 June 2006. The voltage criteria used for voltage security assessment should require, that the worst bus voltage at postcontingency $\mathrm{N}-1$ and sometimes $\mathrm{N}-2$, must be approximately greater than 0.95 p.u. for generator buses and 0.9 p.u. for others. At the stage of planning, the active power transfer margin may be used as a proximity measure of voltage collapse.
\end{abstract}

Keywords: power system control, reactive power control, load flow control, voltage stability

\section{Introduction}

The idea of P-V and Q-V curve is used to determine the maximal reactive margin at load buses to avoid voltage instability. Sometimes the voltage stability study may be limited to identify the violation of the bus voltage constraints. In this paper the $p-q$ curve for the critical bus voltage magnitude is created. Using this $p-q$ curve the probability of the critical voltage violation is estimated for uniformly distributed active and reactive power at a given load bus. The p-q curve is created on the basis of bus impedance, which can be measured or calculated. To illustrate the usefulness of $p-q$ idea the simple numerical example is presented. The paper describes also the importance of reactive power control basing on the failures and control problems in the PPTS during a dry summer period.

Assessing and mitigating problems associated with voltage security remains a critical concern for many power system planners and operators. Since it is well understood that voltage security is driven by the balance of reactive power in a system, it is of particular interest to find out what areas in a system may suffer reactive power deficiencies under some conditions and to obtaining information regarding how system voltage stability can be improved most effectively. Operation near the voltage stability limits is impractical and a sufficient power or voltage margin is needed. Practically, the idea of $\mathrm{P}-\mathrm{V}$ and $\mathrm{Q}-\mathrm{V}$ curve is used to determine the minimal margin to avoid voltage collapse (Chayapathi et al., 2013; Khoi et al., 1999; Lis, 2013).

Voltage stability is concerned with the ability of a power system to maintain acceptable voltages at all buses in the system under normal conditions and after being subjected to a disturbance (Taylor, 1994). As an example, Table 1 shows the voltage limits, which should be fulfilled in PPTS (Lis, 2013). According to their idea, the Thevenin's impedance is equal to the bus load impedance at the point of voltage collapse. In this paper the idea of using Thevenin's impedance to bus voltage study is extended by taking into account the bus load.

Table 1. Voltage Criteria in PPTS

\begin{tabular}{|c|c|c|c|}
\hline No. & Bus & $\begin{array}{l}\text { Normal } \\
\text { Conditions }\end{array}$ & $\begin{array}{l}N-1 \text { and } N-2 \\
\text { Contingencies }\end{array}$ \\
\hline 1 & $\begin{array}{l}\text { Generation } \\
\text { buses } 110 \mathrm{kV}\end{array}$ & $\begin{array}{l}\text { 1.0000p.u. - } \\
1.1100 \text { p.u. }\end{array}$ & $\begin{array}{l}0.9545 \text { p.u. } \\
1.1100 \text { p.u. }\end{array}$ \\
\hline 2 & $\begin{array}{l}\text { Generation } \\
\text { buses } 220 \mathrm{kV}\end{array}$ & $\begin{array}{l}1.0000 \text { p.u. - } \\
1.1136 \text { p.u. }\end{array}$ & $\begin{array}{l}0.9545 \text { p.u. } \\
1.1136 \text { p.u }\end{array}$ \\
\hline 3 & $\begin{array}{l}\text { Generation } \\
\text { buses } 400 \mathrm{kV}\end{array}$ & $\begin{array}{l}1.0000 \text { p.u. - } \\
1.0500 \text { p.u. }\end{array}$ & $\begin{array}{l}0.9500 \text { p.u. } \\
1.0500 \text { p.u. }\end{array}$ \\
\hline 4 & $\begin{array}{l}\text { Load buses } \\
110 \mathrm{kV}\end{array}$ & $\begin{array}{l}0.9545 \text { p.u. - } \\
1.1100 \text { p.u. }\end{array}$ & $\begin{array}{l}0.9000 \text { p.u. } \\
1.1100 \text { p.u. }\end{array}$ \\
\hline 5 & $\begin{array}{l}\text { Load buses } \\
220 \mathrm{kV}\end{array}$ & $\begin{array}{l}0.9545 \text { p.u. - } \\
1.1136 \text { p.u. }\end{array}$ & $\begin{array}{l}0.9091 \text { p.u. } \\
1.1136 \text { p.u. }\end{array}$ \\
\hline 6 & $\begin{array}{l}\text { Load buses } \\
400 \mathrm{kV}\end{array}$ & $\begin{array}{l}0.9500 \text { p.u. - } \\
1.0500 \text { p.u. }\end{array}$ & $\begin{array}{l}0.9000 \text { p.u. } \\
1.0500 \text { p.u. }\end{array}$ \\
\hline
\end{tabular}

From the point of view of monitoring and control the following transmission constraints are the most important: thermal limit of lines of transmission subsystem, voltage stability limit of transmission subsystem and angle stability limit of transmission subsystem. Voltage problems occur in heavily stressed 
power systems. Then, the voltage stability limit may be sometimes more drastically important than thermal limits. This is the case of the voltage collapse in PPTS on June 26, 2006.

This paper is devoted to the analysis of voltage limits. The main question is how far we are from the voltage instability and how to consider the randomness of loads. The original $p-q$ curve is applied here to solve such a task. The idea of using $\mathrm{p}-\mathrm{q}$ curve for voltage collapse analysis was presented in this paper. The $p-q$ curve for the critical bus voltage magnitude is created. Using this $p-q$ curve the critical voltage violation is estimated for uniformly distributed active and reactive power at a given load bus.

The $p-q$ curve is created on the basis of bus impedance. The mathematical background of the proposed idea is presented. To illustrate the usefulness of $\mathrm{p}-\mathrm{q}$ idea the simple numerical example is presented.

\subsection{Country-Wide Absence of Electrical Supply-a Blackout}

The quality of the electrical energy supply can be evaluated basing on a number of parameters (Abril et al., 2003; Yorino et al., 2003; Shubhanga et al., 2002). However, the most important will be always the presence of electrical energy and the number and duration of interrupts. If there is no voltage in the socket nobody will care about harmonics, sags or surges. A long term, wide-spread interrupt - a blackout leads usually to catastrophic losses. It is difficult to imagine that in all the country there is no electrical supply. In reality such things have already happened a number of times.

One of the reason leading to a blackout is reactive power, that went out of the control. When consumption of electrical energy is high, the demand on inductive reactive power increases usually at the same proportion. In this moment, the transmission lines (that are well loaded) introduce an extra inductive reactive power. The local sources of capacitive reactive power become insufficient. It is necessary to deliver more of the reactive power from generators in power plants. It might happen that they are already fully loaded and the reactive power will have to be delivered from more distant places or from abroad. Transmission of reactive power will load more the lines, which in turn will introduce more reactive power. The voltage on customer side will decrease further. Local control of voltage by means of autotransformers will lead to increase of current (to get the same power) and this in turn will increase voltage drops in lines. In one moment this process can go like avalanche reducing voltage to zero. In mean time most of the generators in power plants will switch off due to unacceptably low voltage what of course will deteriorate the situation.

In continental Europe, most of the power plant are based on heat and steam turbines. If a generation unit in such power plant is stopped and cool down it requires time and electrical energy to start operation again. If the other power plants are also off - the blackout is permanent (Bhattacharya et al., 2001, 2002; Chicco et al., 2013).

The difficulties showed up on summer 2006. The prediction for power consumption on this day was $18200 \mathrm{MW}$ (in the morning peak) what was much higher compared with June in last year or previous years. This power was planned to be supplied from 75 generation units. Above these, there were a hot power reserve of $1350 \mathrm{MW}$ (in this $237 \mathrm{MW}$ second-reserve, $656 \mathrm{MW}$ minute-reserve) and a cold reserve of about $2600 \mathrm{MW}$. In the north-east Poland there is not any grid-generation. The closest to this region is Ostroleka Power Plant (P. P.), which in that time from three $200 \mathrm{MW}$ units has two in operation and one set off for maintenance. In early morning of the Jun 26th one unit in Power Plant Patnow had to be switched off and before noon four other units (two in Kozienice P. P. and two in Laziska P. P.) were switched off as well. All these unites were the main supplier to the north-east region of Poland. At 7 o'clock $570 \mathrm{MW}$ of power was lost. At the same time the consumption prediction appeared to be wrong - the consumption was $600 \mathrm{MW}$ higher and there was also much higher demand on reactive power. At 13 o'clock there was an unbalance of $1100 \mathrm{MW}$. In mean time one unit (in Dolna Odra P. P.) had been activated. However further activation from cold-reserve required more time (about 6 hours) because of technological reasons.

Unusual heat wave spreading throughout the country caused deterioration of the operational conditions in power plants. Due to lack of sufficient amount of cooling water and exceeded water temperature levels, the generating capacities of some power plants systematically decreased. That situation concerned mainly the power plants located in the central and northern part of Poland, the loadings of some transmission lines reached the acceptable limits what in turn cause the necessity of generation decrease in power plants located outside the mentioned region. The control of reactive power became critical (Hatziadoniu et al., 2003; Lu et al., 2002).

\section{Prepare Bus Load Flow Equations Using Thevenin's Circuit}

Thevenin's theorem states that in the linear electric circuit the effect of the load change at a given bus can be represented by a simple circuit with emf $\underline{\mathrm{E}}_{\mathrm{T}}$ and the bus impedance $\underline{Z}_{\mathrm{T}}$. The basic circuit resulting from Thevenin's theorem is shown in Figure 1. Knowing the Thevenin's bus impedance $\underline{Z}_{T}=R_{T}+j X_{T}$, load bus voltage $V$, active $P$ and reactive bus power $Q$ one can calculate the magnitude of Thevenin's emf using the following formula: 


$$
E_{T}=\sqrt{\left(V+\frac{P R_{T}+Q X_{T}}{V}\right)^{2}+\left(\frac{P X_{T}-Q R_{T}}{V}\right)^{2}}
$$

Using complex notification:

$$
\begin{gathered}
\underline{V}=V_{a}+j V_{b} \text { and } V=\sqrt{V_{a}^{2}+V_{b}^{2}} \\
\underline{E}_{T}=E_{a}+j E_{b} \text { and } E_{T}=\sqrt{E_{T a}^{2}+E_{T b}^{2}}
\end{gathered}
$$

a)

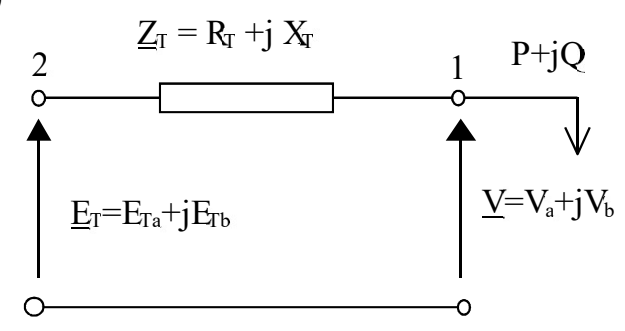

b)

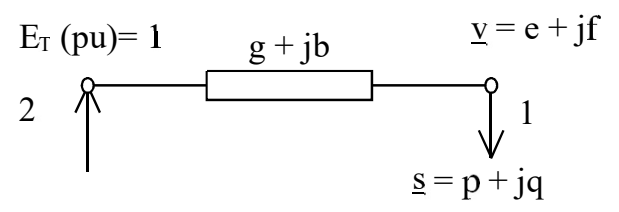

Figure 1. The scheme of 2-bus Thevenin's network, a) simple Thevenin's circuit, b) scheme for load flow study.

The complex admittance of branch connecting load bus with Thevenin's emf bus equals:

$$
G_{T}+j B_{T}=1 /\left(R_{T}+j X_{T}\right)
$$

The load flow equations for load bus have the following form:

$$
\begin{aligned}
& P=V^{2} G_{11}+\left(V_{a} E_{a}+V_{b} E_{b}\right) G_{12}+\left(-V_{a} E_{b}+V_{b} E_{a}\right) B_{12} \\
& \text { where } \quad \begin{array}{l}
V^{2} B_{11}-\left(V_{a} E_{a}+V_{b} E_{b}\right) B_{12}+\left(-V_{a} E_{b}+V_{b} E_{a}\right) G_{12} \\
\qquad G_{11}=G_{T} \text { and } G_{12}=-G_{T} \\
\qquad B_{11}=B_{T} \text { and } B_{12}=-B_{T}
\end{array}
\end{aligned}
$$

Let the bus 2 with Thenenin's emf be the slack bus. Then I have

$$
\begin{gathered}
E_{a}=E_{T} \text { and } E_{b}=0 \\
\text { and } \quad P=V^{2} G_{11}+V_{a} G_{12}+V_{b} B_{12} \\
Q=-V^{2} B_{11}-V_{a} B_{12}+V_{b} G_{12}
\end{gathered}
$$

or

$$
\begin{gathered}
P=V^{2} G_{T}-V_{a} G_{T}-V_{b} B_{T} \\
Q=-V^{2} B_{T}+V_{a} B_{T}-V_{b} G_{T}
\end{gathered}
$$

To simplify all considerations the load bus per unit system is introduced as follows

$$
\begin{gathered}
Z_{b}=Z_{T}=\sqrt{R_{T}^{2}+X_{T}^{2}} \\
V_{\text {base }}=E_{T} \\
S_{b}=E_{T}^{2} / Z_{b}
\end{gathered}
$$

where symbol $b$ means the base value. Dividing both side of load flow equations by $S_{b}$ I obtain:

$$
\begin{gathered}
p=v^{2} g-e g-f b \\
q=-v^{2} b+e b-f g \\
\text { where } p=P / S_{b} \text { and } q=Q / S_{b} \\
v=V / E_{T} \\
e=V_{a} / E_{T} \text { and } f=V_{b} / E_{T} \\
g=G_{T} Z_{T} \text { and } b=B_{T} Z_{T}
\end{gathered}
$$

Note that the following relations exist in the new bus load per unit system:

$$
\begin{gathered}
r+j x=R_{T} / Z_{T}+j X_{T} / Z_{T} \\
z^{2}=r^{2}+x^{2}=\frac{R_{T}^{2}}{Z_{T}^{2}}+\frac{X_{T}^{2}}{Z_{T}^{2}}=1 \\
\underline{y}=1 / \underline{z}=1 /(r+j x)=(r-j x) / z^{2}=r-j x \\
\underline{y}=g+j b
\end{gathered}
$$

And finally $g=r$ and $b=-x$

Hence the load flow equations in load bus per unit are as follows:

$$
\begin{gathered}
p=v^{2} r-e r+f x \\
q=v^{2} x-e x-f r
\end{gathered}
$$




\subsection{The P-Q Curve for the Critical Bus Voltage Magnitude}

From the point of view of voltage stability the voltage magnitude at a given bus must be in the range of upper and lower voltage limit

$$
V_{\text {lower }} \leq V \leq V_{\text {upper }}
$$

Especially the lower value is the critical value $V_{c r}$ from the point of view of avoiding voltage instability in the power system. Hence the bus voltage must be greater then the critical value

$$
V>V_{c r}
$$

Using the new per unit system I can write

$$
v>v_{c r}
$$

where

$$
v_{c r}=V_{c r} / E_{T}
$$

According to the above assumptions load flow equations for load bus critical solutions (e,f) depend on the critical voltage magnitude vcr. The load flow equations can be analyzed as a critical $p-q$ curve composed of $(\mathrm{p}, \mathrm{q})$ values, which are related to the critical bus voltage magnitude vcr .

To find the formula of the critical p-q curve I must eliminate the rectangular components of $e$ and $f$ from the load flow equations (28) and (29). To find $e$ I can make the following multiplications

$$
\begin{aligned}
& r p=r^{2} v^{2}-r^{2} e+r x f \\
& x q=x^{2} v^{2}-x^{2} e-r x f
\end{aligned}
$$

and the following addition

$$
r p+x q=z^{2} v^{2}-z^{2} e
$$

For $z=1 \mathrm{I}$ have finally

$$
e=v^{2}-(r p+x q)
$$

To find $f$ I can made the following multiplications

$$
\begin{aligned}
& x p=r x v^{2}-r x e+x^{2} f \\
& r q=r x v^{2}-r x e-r^{2} f
\end{aligned}
$$

and the following subtraction

$$
x p-r q=z^{2} f
$$

For $z=1$ I have finally

$$
f=x p-r q
$$

Substituting the obtained formula of $e$ and $f$ to the formula of $v_{c r}$ I have as follows

$$
\begin{gathered}
v_{c r}^{2}=e^{2}+f^{2} \\
v_{c r}^{2}=\left(v_{c r}^{2}-(r p+x q)\right)^{2}+(x p-r q)^{2} \\
v_{c r}^{2}=v_{c r}^{4}-2 v_{c r}^{2}(r p+x q) \\
+(r p+x q)^{2}+(x p-r q)^{2} \\
v_{c r}^{2}=v_{c r}^{4}-2 v_{c r}^{2} r p-2 v_{c r}^{2} x q \\
+r^{2} p^{2}+2 r x p q+x^{2} q^{2} \\
+x^{2} p^{2}-2 r x p q+r^{2} q^{2} \\
v_{c r}^{2}=v_{c r}^{4}-2 v_{c r}^{2} r p-2 v_{c r}^{2} x q+p^{2}+q^{2}
\end{gathered}
$$

Hence, I obtain the following formula of $\mathrm{p}-\mathrm{q}$ curve for a critical voltage magnitude $v_{c r}$

$$
p^{2}+q^{2}-2 v_{c r}^{2} r p-2 v_{c r}^{2} x q+v_{c r}^{4}-v_{c r}^{2}=0
$$

From the above formula I can obtain the quadratic equations for the specific $p$

$$
q^{2}-2 v_{c r}^{2} x q+p^{2}-2 v_{c r}^{2} r p+v_{c r}^{4}-v_{c r}^{2}=0
$$

An example of $p-q$ curve is shown in Figure 2. The $\mathrm{p}-\mathrm{q}$ curve can be transformed into P-Q curve after multiplication $p$ and $q$ by $S_{b}$.

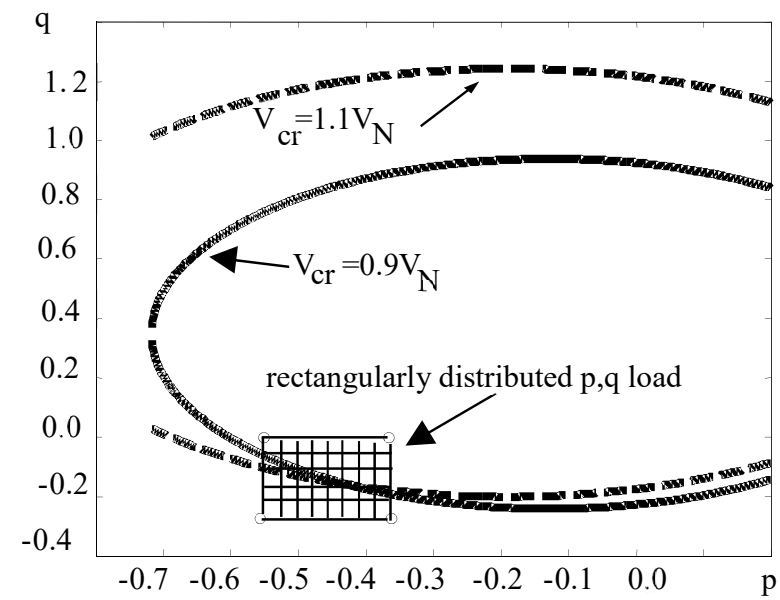

Figure 2. The example p-q curve at a load bus. Symbol $\mathrm{V}_{\mathrm{N}}$ means the nominal voltage.

Equation (48) is quadratic and has two real solutions according to the value of the equation discriminant $\Delta$ :

$$
\Delta=4 v_{c r}^{4} x^{2}-4 p^{2}+8 v_{c r}^{2} r p-4 v_{c r}^{4}+4 v_{c r}^{2}
$$




$$
\begin{gathered}
\Delta=4 v_{c r}^{4} x^{2}-4 p^{2}+8 v_{c r}^{2} r p-4 z^{2} v_{c r}^{4}+4 v_{c r}^{2} \\
\Delta=4 v_{c r}^{4} x^{2}-4 p^{2}+8 v_{c r}^{2} r p-4 r^{2} v_{c r}^{4}-4 x^{2} v_{c r}^{4}+4 v_{c r}^{2} \\
\Delta=-4 p^{2}+8 v_{c r}^{2} r p-4 r^{2} v_{c r}^{4}+4 v_{c r}^{2} \\
\Delta=4 v_{c r}^{2}-4\left(p^{2}-2 v_{c r}^{2} r p+r^{2} v_{c r}^{4}\right) \\
\Delta=4 v_{c r}^{2}-4\left(p-v_{c r}^{2} r\right)^{2} \\
\sqrt{\Delta}=2 \sqrt{v_{c r}^{2}-\left(p-r v_{c r}^{2}\right)^{2}}
\end{gathered}
$$

and finally I obtain two parts of p-q curve

$$
q_{1,2}=0.5\left(2 v_{c r}^{2} x-/+\sqrt{\Delta}\right) \text {. }
$$

The lower part of the p-q curve is associated with the consumed power, because a reactive consumed power at bus is treated in load flow equations as a negative value

$$
q_{\text {lower }}=v_{c r}^{2} x-\sqrt{-p^{2}+2 v_{c r}^{2} r p+v_{c r}^{2}-v_{c r}^{4} r^{2}}
$$

The upper part of the $p-q$ curve relates to positive values, i.e. to reactive generation at a given bus

$$
q_{\text {upper }}=v_{c r}^{2} x+\sqrt{-p^{2}+2 v_{c r}^{2} r p+v_{c r}^{2}-v_{c r}^{4} r^{2}}
$$

\subsection{The Probability of the Violation of the Critical Voltage}

Let's assume that the load at bus is uniformly distributed between their min and max

$$
\begin{aligned}
& p_{\text {min }} \leq p \leq p_{\text {max }} \\
& q_{\text {min }} \leq q \leq q_{\text {max }}
\end{aligned}
$$

The probability of the violation of the critical voltage magnitude at load bus can be calculated using the outside area and the rectangular area, see Figure 3. To find the probability of the violation of the critical voltage the lower part of p-q curve should be used, Figure 3. Using the geometrical definition of probability:

$$
p_{\text {vcr }}=S_{\text {outside }} / S
$$

where $S$ means the area of rectangular

$$
S=\left(p_{\max }-p_{\min }\right)\left(q_{\max }-q_{\min }\right)
$$

The outside area equals

$$
S_{\text {outside }}=S-S_{A B C D}
$$

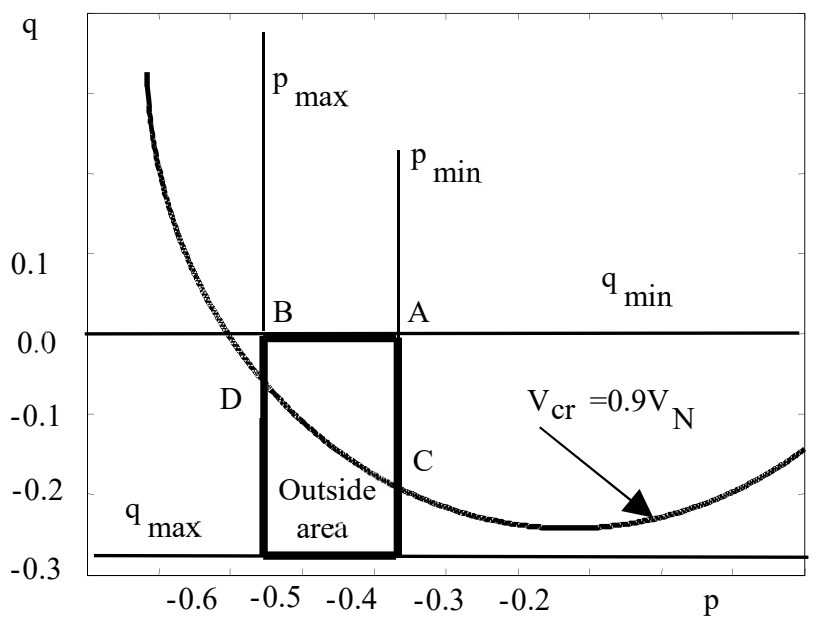

Figure 3. The $p-q$ curve and the rectangularly distributed load.

The area of $A B C D$ figure can be computed using the definite integral formula in the following way

$$
S_{A B C D}=S 1-S 2=\int_{p \max }^{p \min } q_{\min } d p-\int_{p \max }^{p \min } q_{\text {lower }} d p
$$

where

$$
S 1=\int_{p \max }^{p \min } q_{\min } d p=\left.q_{\min } p\right|_{p \text { max }} ^{p \min }=q_{\text {min }}\left(p_{\text {min }}-p_{\text {max }}\right)
$$

and

$$
\begin{aligned}
S 2 & =v_{c r}^{2} x\left(p_{\min }-p_{\max }\right)+ \\
& -\frac{\left(-p_{\min }+v_{c r}^{2} r\right)}{2} \sqrt{W_{\text {min }}}+ \\
& +\frac{\left(-p_{\max }+v_{c r}^{2} r\right)}{2} \sqrt{W_{\max }}+ \\
& +\frac{v_{c r}^{2}}{2} \arcsin \frac{\left(-p_{\min }+v_{c r}^{2} r\right)}{v_{c r}}+ \\
& -\frac{v_{c r}^{2}}{2} \arcsin \frac{\left(-p_{\max }+v_{c r}^{2} r\right)}{v_{c r}}
\end{aligned}
$$

Finally we can make the following substitution:

$$
\begin{gathered}
W_{\text {min }}=-p_{\text {min }}^{2}+2 v_{c r}^{2} r p_{\text {min }}+v_{c r}^{2}-v_{c r}^{4} r^{2} \\
W_{\text {max }}=-p_{\text {max }}^{2}+2 v_{c r}^{2} r p_{\text {max }}+v_{c r}^{2}-v_{c r}^{4} r^{2}
\end{gathered}
$$

\section{Numerical Example}

Thevenin's complex impedance seen from the $400 \mathrm{kV}$ load bus has been obtained by the load flow study in $400 / 220 \mathrm{kV}$ transmission grid:

$$
\underline{Z}_{T}=R_{T}+j X_{T}=(-125.12+31.40) \Omega .
$$

The bus voltage magnitude at the analysed load bus determined by load flow computation equals: $V=410$ 
$\mathrm{kV}$, while the nominal voltage has the following value $V_{N}=400 \mathrm{kV}$. The critical voltage magnitude equals:

$$
V_{c r}=0.9 V_{N}=360 \mathrm{kV} \text {. }
$$

The minimal and maximal active and reactive load at the analysed bus equal

$$
\begin{gathered}
P_{\min }=400 \mathrm{MW} \text { and } P_{\max }=600 \mathrm{MW} ; \\
Q_{\min }=0 \mathrm{MVAR} \text { and } P_{\max }=300 \mathrm{MVAR} .
\end{gathered}
$$

Knowing the Thevenin's bus impedance $\underline{Z}_{T}=R_{T}+$ $j X_{T}$, load bus voltage $V$, active $P$ and reactive bus power $Q$ I calculate the magnitude of Thevenin's emf:

$$
E_{T}=\sqrt{\left(V+\frac{P R_{T}+Q X_{T}}{V}\right)^{2}+\left(\frac{P X_{T}-Q R_{T}}{V}\right)^{2}}=572.9 \mathrm{kV} .
$$

To simplify all considerations the load bus per unit system is introduced: $Z_{b}=Z_{T}=\sqrt{R_{T}^{2}+X_{T}^{2}}=342.1 \Omega$;

$$
\begin{gathered}
V_{\text {base }}=E_{T}=572.9 \mathrm{kV} ; \\
S_{b}=E_{T}^{2} / Z_{b}=959.4 \mathrm{MVA} .
\end{gathered}
$$

The value of analyzed variables in load by per unit systems are as follows:

$$
\begin{gathered}
p_{\min }=P_{\min } / S_{b}=-0.4169 ; \\
p_{\max }=P_{\max } / S_{b}=-0.6254 ; \\
q_{\min }=Q_{\min } / S_{b}=0 ; q_{\max }=Q_{\max } / S_{b}=-0.3127 ; \\
v_{c r}=V_{c r} / E_{T}=0.6284 ; \\
r=R_{T} / Z_{T}=-0.3657 ; x=X_{T} / Z_{T}=0.9307 .
\end{gathered}
$$

Now can calculate the probability of the violation of the critical voltage magnitude. The rectangular area:

$$
S=\left(p_{\max }-p_{\min }\right)\left(q_{\max }-q_{\min }\right)=0.0652 .
$$

The inside area: $S_{A B C}=\int_{p_{\min }}^{p_{\max }}\left(q_{\text {lower }}-q_{\min }\right) d p=0.0270$.

The outside area $S_{\text {outside }}=S-S_{A B C D}=0.0382$.

The probability of the violation of the critical voltage magnitude: $p_{v c r}=S_{\text {outside }} / S=0.58$

\section{Conclusions}

The proposed p-q curve method is simple and may be based on local measurements of bus impedance. It enables calculating the probability of voltage limit violation at a given load bus. The greater the probability the weaker the bus is from the point of view of voltage stability.

To find the formula of p-q curve a new load bus per unit system must be introduced. The transformation from $\mathrm{p}-\mathrm{q}$ curve to $\mathrm{P}-\mathrm{Q}$ curve can be easily made by multiplication $p$ and $q$ value by the base power of the analyzed load bus.

The probability of voltage limit violation is estimated as the quotient of relevant area outside and inside the specific p-q curve.

The slower forms of voltage instability can be analyzed as steady state problem using power flow simulation. Snapshot in time following an outage may be simulated and P-U curves computed to assess voltage stability margin.

The main difficulties of the modelling of the power system concern load modelling and therefore conservative constant load hypothesis are used in computation.

\section{Acknowledgements}

This research was performed in cooperation with the Polish Power Grid Operator: PSE Operator S.A., Warszawska 165, 05-520 Konstancin-Jeziorna, Poland.

\section{References}

P. I. Abril, J. A. G. Quintero. VAR compensation by sequential quadratic programming. IEEE Trans. on Power Systems, 18:36-41, 2003. doi:10.1109/TPWRS.2002.8070 49.

K. Bhattacharya, J. Zhong. Reactive power as an ancillary service. IEEE Trans. on Power Systems, 16:294-300, 2001. doi:10.1109/59.918301.

K. Bhattacharya, J. Zhong. Reactive power management in deregulated electricity markets - a review. In conference proceedings: IEEE Power Eng. Soc. Winter Meeting, New York, 2002. doi: 10.1109/PESW.2002.985223.

V. Chayapathi, B. Sharath, G. S. Anitha. Voltage Collapse Mitigation by Reactive Power Compensation at the Load Side. Ijret, available via http://www.ijret.org, 02(09), 2013. doi: 10.15623/ijret.2013.0209037.

G. Chicco, G. Gross. Allocation of the reactive power support requirements in multitransaction networks. IEEE Transactions on Power Systems, 17:243-249, 2012.

C. J. Hatziadoniu, N. Nikolov, F. Pourboghrat. Power Conditioner Control and Protection for Distributed Generators and Storage. IEEE Trans. on Power Systems, 18:83-90, 2003.

Vu Khoi, M. M. Begovic, D. Novosel, M. M. Saha. Use of local measurements to estimate voltage stability margin. IEEE Trans. on Power Systems, 14:1029-1035, 1999.

R. Lis. Problems of assessment and ways of improving voltage stability of an electrical power transmission grid. Monograph, Wroclaw University of Technology Press. 2013. ISSN 0324-976x.

R. Lis. Voltage Stability Assessment Using Bus P-Q Curve. Mathematics and Computers in Contemporary Science. 2013. ISBN: 978-960-474-356-8

Y. Lu, A. Abur. Static security enhancement via optimal utilization of thyristor-controlled series capacitors. IEEE Trans. on Power Systems, 17:324-329, 2002.

K.N. Shubhanga, A. M. Kulkarni. Application of structure preserving energy margin sensitivity to determine the effectiveness of shunt and series FACTS devices. IEEE Trans. on Power Systems, 17:730-738, 2002.

C.W. Taylor, Power System Voltage Stability. McGraw-Hill. 1994.

N. Yorino, E. E. El-Araby. Sasaki and S. Harada. A new formulation for FACTS allocation for security enhancement against voltage collapse. IEEE Trans. on Power Systems, 18:3-10, 2003. doi: 10.1109/TPWRS.2002.804921. 